\title{
Susceptibilidade antimicrobiana de Campylobacter fetus subsp. venerealis isolado de bovinos ${ }^{1}$
}

\author{
Agueda C. Vargas ${ }^{2}$, Mateus M. Costa ${ }^{2}$, Ana C.M. Groff ${ }^{2}$, Luciane R. Viana ${ }^{4}$, Cristina \\ C. Krewer ${ }^{2}$, Denis A. Spricigo ${ }^{2}$ e Jackeline K. Kirinus ${ }^{6}$
}

\begin{abstract}
Vargas A.C., Costa M.M., Groff A.C.M., Viana L.R., Krewer C.C., Spricigo D.A. \& Kirinus J.K. 2005. [Antimicrobial susceptibility of Campylobacter fetus subsp. venerealis isolated from cattle.] Susceptibilidade antimicrobiana de Campylobacter fetus subsp. venerealis isolado de bovinos. Pesquisa Veterinária Brasileira 25(1):1-3. Laboratório de Bacteriologia do Departamento de Medicina Veterinária Preventiva, Universidade Federal de Santa Maria, 97105-900 Santa Maria, RS, Brazil.E-mail:gueda@ccr.ufsm.br

Venereal campylobacteriosis is associated with infection of Campylobacter fetus subsp. fetus and Campylobacter fetus subsp. venerealis. The etiological agent is transmitted by natural bull breeding or artificial insemination using contaminated semen. The present study aimed to determine the in vitro susceptibility of $C$. fetus subsp. venerealis isolates to antimicrobial drugs generally used in clinical and semen treatment. Reference strains of $C$. fetus subsp. fetus and $C$. fetus subsp. venerealis and 21 C. fetus isolates were tested. The susceptibility test was performed by using the modified KirbyBauer diffusion disc method. C. fetus subsp. fetus reference strain was resistant to lincomycin and penicillin. C. fetus subsp. venerealis was susceptible to all antimicrobial tested, with exception to C.C. KrewerDnalidixic acid. C. fetus subsp. venerealis samples were sensible to amikacin, ampicillin, cefalotin, streptomycin, gentamycin, penicillin and tetracycline. Drug resistance was observed on $42.86 \%$ of lincomycin, $4,76 \%$ of enrofloxacin, and $100 \%$ to nalidixic acid. In addition $4.76 \%$ of the isolates showed intermediate susceptibility to enrofloxacin, neomycin, polimixin B and $9.52 \%$ to lincomycin. The susceptibility of $C$. fetus isolates to antimicrobial drugs commonly used in clinical and semen treatment was demonstrated.
\end{abstract}

INDEX TERMS: Campylobacteriosis, cattle, semen, antibiomicrobials.

RESUMO.- A campilobacteriose venérea bovina, ocasionada principalmente pelo Campylobacter fetus subsp. fetus e Campylobacter subsp. venerealis, é transmitida através do coito ou por inseminação com sêmen contaminado. $O$ propósito deste estudo foi determinar a susceptibilidade in vitro de isolados de $C$. fetus subesp. venerealis a agentes antimicrobianos comumente utilizados para o tratamento clínico e de sêmen. Foram testadas duas cepas padrão, sendo uma de $C$. fetus subsp.

\footnotetext{
${ }^{1}$ Recebido em 16 de novembro de 2003.

Aceito para publicação em 23 de maio de 2004.

2 Depto Medicina Veterinária Preventiva, UFSM, Santa Maria, 97105-900 RS. E-mail: agueda@ccr.ufsm.br

${ }^{3}$ Doutorando em Biologia Celular e Molecular, Centro de Biotecnologia, UFRGS, Porto Alegre, RS.

${ }^{4}$ Médica Veterinária.

${ }^{5}$ Farmacêutica Bioquímica.

${ }^{6}$ Acadêmica em Medicina Vaterinária, UFSM, bolsista CNPq.
}

fetus e outra de $C$. fetus subsp. venerealis, bem como 21 amostras de isolados clínicos de $C$. fetus subsp. venerealis. Os testes foram realizados conforme o método de Kirby-Bauer. A amostra padrão de $C$. fetus subsp. fetus demonstrou-se resistente à lincomicina, penicilina e ácido nalidíxico, enquanto a de $C$. fetus subsp. venerealis apresentou susceptibilidade a todos antimicrobianos testados, com exceção do ácido nalidíxico. Todas as amostras de $C$. fetus subsp. venerealis foram susceptíveis à amicacina, ampicilina, cefalotina, estreptomicina, gentamicina, penicilina e tetraciclina. Foi observada resistência de $42,86 \%$ à lincomicina e $4,76 \%$ a enrofloxacina, e de $100 \%$ ao ácido nalidíxico. Ainda, $4,76 \%$ apresentaram susceptibilidade intermediária à enrofloxacina, neomicina e polimixina $\mathrm{B} e$ $9,52 \%$ à lincomicina. Os resultados evidenciaram a sensibilidade das amostras analisadas aos antimicrobianos comumente utilizados para o tratamento clínico e do sêmen.

TERMOS DE INDEXAÇÃO: Campilobacteriose, bovinos, sêmen, antimicrobianos. 


\section{INTRODUÇÃO}

Infecções bacterianas do trato genital bovino são causas reconhecidas de baixos índices de produtividade, tendo assim especial significado econômico. Uma das enfermidades infecciosas associada ao baixo desempenho reprodutivo do rebanho é a campilobacteriose venérea bovina (CVB), causada pelo Campylobacter fetus subsp. fetus e Campylobacter subsp. venerealis. O habitat natural do $C$. fetus subsp. venerealis é o trato reprodutivo, podendo ser encontrado na glande, porção distal da uretra e prepúcio dos touros, e na vagina, cérvix, útero e ovidutos de novilhas e vacas. A infecção nas fêmeas causa aborto e infertilidade (Eagleasome \& Garcia 1992). A transmissão em condições naturais ocorre através do coito, ou por inseminação com sêmen contaminado (Garcia \& Brooks 1993).

A terapia com antimicrobianos tem sido recomendada principalmente para o tratamento de touros infectados, e em menor escala para vacas. A estreptomicina e a penicilina são as drogas mais utilizadas para o controle de infecções por Campylobacter fetus (Garcia et al. 1983, Hum et al. 1993). Também recomenda-se tratar o sêmen, sendo que a campilobacteriose venérea foi a razão original da adição de antibióticos neste (Dias 2003). Estudos recentes apontam para o aumento da resistência de microrganismos às drogas que são usadas como agentes terapêuticos. Este é um problema crescente, indicando assim a necessidade da adoção de medidas para reduzir esta resistência, assim como controlar mais efetivamente o uso de antibióticos, pesquisar os mecanismos genéticos de resistência, estudar a susceptibilidade microbiana e desenvolver novas drogas (Nascimento et al. 2000).

A resistência microbiana pode ser associada a um aumento na virulência da cepa, resultante da aquisição de genes com fatores de resistência, e também pela escolha empírica do agente de tratamento, antes do teste de susceptibilidade (Travers \& Barza 2002). $O$ uso indiscriminado de antimicrobianos, as subdosagens, a adição de promotores de crescimento à dieta, que expõe os animais por longos períodos a pequenas concentrações de antibióticos, podem colaborar para a seleção e manutenção de organismos resistentes (McEwen \& Fedorka-Cray 2002).

O propósito deste estudo foi determinar a susceptibilidade in vitro de isolados de Campylobacter fetus subsp. venerealis a agentes antimicrobianos, visando gerar subsídios para a avaliação da conduta utilizada na terapêutica de animais infectados e tratamento do sêmen a ser utilizado em inseminação artificial.

\section{MATERIAL E MÉTODOS}

Duas cepas padrão, sendo uma de Campylobacter fetus subsp. fetus (ATCC 27374) e outra de Campylobacter fetus subsp. venerealis (ATCC 19438), e 21 amostras de $C$. fetus subsp. venerealis previamente isoladas e caracterizadas fenotípica e molecularmente por Vargas et al. (2003) foram utilizadas.

$\mathrm{O}$ teste de sensibilidade aos antimicrobianos foi executado conforme Bauer et al. (1966). Colônias de Campylobacter fetus foram ressuspendidas em caldo Muller Hinton (MH caldo) e ajustadas na turvação da escala 0,5 de MacFarland. Logo após, $100 \mathrm{ml}$ (aprox. 10 Unidades Formadoras de Colônia - UFC) de inóculo foram semeados em placas de $\mathrm{MH}$ ágar com alça de Drigalsky e os discos de antimicrobianos (ácido nalidíxico, amicacina, ampicilina, cefalotina, enrofloxacina, estreptomicina, gentamicina, lincomicina, neomicina, penicilina, polimixina $\mathrm{B}$, tetraciclina) distribuídos. As placas foram incubadas em microaerofilia a $37^{\circ} \mathrm{C}$ por 48 horas, quando se realizou a leitura da sensibilidade através de medição dos halos de inibição do crescimento bacteriano. Para controle de qualidade do teste foram utilizadas amostras padrão de Staphylococcus aureus (ATCC 25923), Pseudomonas aeruginosa (ATCC 27853) e de Escherichia coli (ATCC 25922). O parâmetro de susceptibilidade NCCLS para organismos aeróbicos foi utilizado.

\section{RESULTADOS E DISCUSSÃO}

As cepas padrão de Staphylococcus. aureus, Pseudomonas aeruginosa e Escherichia coli, utilizadas no controle de qualidade do teste, apresentaram os resultados preconizados pela NCCLS. A amostra padrão de Campylobacter fetus subsp. fetus demonstrou resistência à lincomicina, penicilina e ao ácido nalidíxico, enquanto a de Campylobacter fetus subsp. venerealis apresentou susceptibilidade a todos antimicrobianos testados, com exceção do ácido nalidíxico. Todos os 21 isolados de $C$. fetus subsp. venerealis testados foram susceptíveis a amicacina, ampicilina, cefalotina, estreptomicina, gentamicina, penicilina e tetraciclina. Entretanto, foi observada resistência de $42,86 \%$ a lincomicina, $4,76 \%$ a enrofloxacina, e de $100 \%$ ao ácido nalidíxico. Ainda, 4,76\% apresentaram susceptibilidade intermediária a enrofloxacina, neomicina, polimixina B e 9,52\% a lincomicina (Quadro 1).

C. fetus é susceptível à cefalotina e resistente ao ácido nalidíxico, sendo este um critério de diferenciação fenotípica entre as espécies de Campylobacter (Quinn et al. 1994). No entanto, os testes de caracterização fenotípica devem ser utilizados com cautela, pois podem induzir erros de identificação, uma vez que a resistência aos antimicrobianos pode ser adquirida por transdução ou mutações (On \& Harrington 2001). No presente trabalho, todas as amostras testadas preservaram o padrão de sensibilidade à cefalotina, viabilizando este teste como um critério para identificação fenotípica.

A susceptibilidade de $95,24 \%$ de $C$. fetus subsp. venerealis à polimixina B foi semelhante aos resultados citados por Hum et al. (1994). Estes autores sugerem que este fato possa ser responsável pelas limitações das técnicas de diagnóstico da CVB através de isolamento, uma vez que a maioria dos meios de transporte e

Quadro 1. Perfil de susceptibilidade das 21 amostras de Campylobacter fetus subsp. venerealis in vitro

\begin{tabular}{cccc}
\hline Antimicrobiano & $\begin{array}{c}\text { Susceptibilidade } \\
(\%)\end{array}$ & $\begin{array}{c}\text { Susceptibilidade } \\
\text { intermediária (\%) }\end{array}$ & $\begin{array}{c}\text { Resistência } \\
(\%)\end{array}$ \\
\hline Ácido nalidíxico & 0 & 0 & 100 \\
Amicacina & 100 & 0 & 0 \\
Ampicilina & 100 & 0 & 0 \\
Cefalotina & 100 & 0 & 0 \\
Enrofloxacina & 90,47 & 4,76 & 4,76 \\
Estreptomicina & 100 & 0 & 0 \\
Gentamicina & 100 & 0 & 0 \\
Lincomicina & 47,62 & 9,52 & 42,86 \\
Neomicina & 95,24 & 4,76 & 0 \\
Penicilina & 100 & 0 & 0 \\
Polimixina B & 95,24 & 4,76 & 0 \\
Tetraciclina & 100 & 0 & 0
\end{tabular}


cultura possui a polimixina B em sua composição. Entretanto, contrariando esta tese, todos os isolados analisados neste trabalho foram obtidos a partir de meio de transporte contendo polimixina B. Esse achado provavelmente se deve à presença deste antimicrobiano no meio de transporte e enriquecimento, em concentração inferior a MIC (concentração inibitória mínima) do disco utilizado para o teste.

O elevado percentual de amostras resistentes à lincomicina $(42,86 \%)$, não é um fato inesperado, tendo em vista a menor atividade deste antimicrobiano contra microrganismos Gramnegativos (Prescott 1993). A escassez de dados a respeito do perfil de susceptibilidade antimicrobiana de $C$. fetus subsp. venerealis, dificulta comparações com resultados de outros autores, no entanto em trabalhos com C. fetus subsp. fetus, Kwon et al. (1994) encontraram 100\% de susceptibilidade à gentamicina $\mathrm{e}$ tetraciclina, enquanto $88 \%$ foram susceptíveis à ampicilina, em 25 amostras testadas frente a 14 antimicrobianos. Já Tremblay et al. (2003), relataram uma sensibilidade de $100 \%$ para ampicilina e gentamicina e resistência de 34\% à tetraciclina em 111 amostras dessa mesma subespécie.

Prescott \& Baggot (1993) sugerem a estreptomicina como droga de escolha para o tratamento de $C$. fetus subsp. venerealis, sendo eficaz para eliminar o estado de portador do touro. Por sua vez Hum et al. (1993), indicam a associação de penicilina e estreptomicina para o mesmo fim. Os resultados encontrados neste estudo ( $100 \%$ de sensibilidade a estreptomicina e penicilina), sustentam a indicação da terapia citada anteriormente.

Em trabalhos semelhantes Shin (1985) e Chen (1990), testaram duas associações de antibióticos (penicilina-estreptomicinapolimixina B e penicilina-estreptomicina-lincomicinaespectinomicina) para eliminar $C$. fetus no sêmen artificialmente contaminado, encontrando eficiente controle desta bactéria nas amostras testadas. $\mathrm{O}$ tratamento do sêmen com a combinação de gentamicina, lincomicina, espectinomicina e tilosina por 3-5 minutos é capaz de inativar $C$. fetus subsp. venerealis sem prejuízo à fertilidade (Egleasome \& Garcia 1995). Embora o percentual de resistência à lincomicina tenha sido alto, esta é utilizada em associações com a função de eliminar outros patógenos presentes no sêmen. Os antibióticos comumente utilizados no sêmen mostraram-se também eficientes nas amostras de $C$. fetus subsp. venerealis testadas, o que confirma a necessidade de sua adição para controle desta bactéria.

O sêmen destinado à comercialização deve ser processado de acordo com as recomendações do Código Zoosanitário Internacional da OIE (Organização Internacional para a Saúde Animal), que prevê adição de gentamicina ( $250 \mathrm{mg})$, tilosina (50 $\mathrm{mg})$, lincomicina-espectinomicina (150-300 $\mathrm{mg}$ ) ou penicilina (500 UI), estreptomicina (500 UI) e lincomicina-espectinomicina (150$300 \mathrm{mg}$ ) por mililitro de sêmen congelado (Brasil 2003). Este trabalho comprova que essas associações de antibióticos são eficientes no controle do $C$. fetus subsp. venerealis, também quando usado no tratamento do sêmen. Assim, a inseminação artificial poderia prevenir a disseminação da enfermidade pela adição das drogas recomendadas no sêmen.

Apesar de algumas amostras de $C$. fetus mostrarem-se resistentes à ação de certos antimicrobianos testados, a grande mai- oria demonstrou sensibilidade. Os resultados indicam que as amostras de $C$. fetus testadas são sensíveis aos antibióticos comumente indicados para o tratamento clínico e do sêmen.

\section{REFERÊNCIAS}

Bauer A.W., Kirby W.M.M., Sherris J.C. \& Turck M. 1996. Antibiotic susceptibility testing by standardized single method. Am. J. Clin. Pathol. 45:493-496.

Brasil 2003. Ministério da Agricultura, Pecuária e Abastecimento, Portaria/SDA $n^{\circ} 46$, de 30 de julho de 2003.

Chen S.S., Redwood D.W. \& Ellis B. 1990. Control of Campylobacter fetus in artificially contaminated bovine semen by incubation with antibiotics before freezing. Brit. Vet. J. 146(1):68-74.

Dias R.O.S. Doenças transmissíveis pelo sêmen. Capturado em 27 de jul. 2003. Online. Disponível na Internet htpp:/www.milkpoint.com.br

Eaglesome M.D. \& Garcia M.M. 1995. Comparisons of antibiotics to control Pseudomonas aeruginosa in bovine semen. Can. J. Vet. Res. 59:73-75.

Eaglesome M.D. \& Garcia M.M. 1992. Microbial agents associated with bovine genital tract infections and semen. Part I. Brucella abortus, Leptospira, Campylobacter fetus and Tritrichomonas foetus . Vet. Bull. 62(8):743775.

Garcia M.M. \& Brooks B.W. 1993. Campylobacter, p.262-272. In: Gyles C.L. \& Thoen C.O. (ed.) Pathogenesis of Bacterial Infections in Animals. Iowa State University Press, Ames.

Garcia M.M., Eaglesome M.D. \& Rigby C. 1983. Campylobacters important in veterinary medicine. Vet. Bull. 53(9):793-817.

Hum S., Brunner J. \& Gardiner B. 1993. Failure of therapeutic vaccination of a bull infected with Campylobacter fetus. Aust. Vet. J. 70(10):386-387.

Hum S., Brunner J., McInnes A., Mendoza G. \& Stephens J. 1994. Evaluation of cultural methods and selective media for the isolation of Campylobacter fetus subsp. venerealis from cattle. Aust. Vet. J. 71(6):184-186.

Kwon S., Cho D.H., Lee S.Y., Lee K. \& Chong Y. 1994. Antimicrobial susceptibility of Campylobacter fetus subsp. fetus isolated from blood and synovial fluid. Yonsei Med. J. 35(3):314-319.

McEwen S.A. \& Fedorka-Cray P.J. 2002. Antimicrobial Use and Resistance in Animals. Clin. Infect. Dis. 34(3):93-106.

Nascimento G.G.F., Locatelli J., Freitas P.C. \& Silva G.L. 2000. Antibacterial activity of plant extracts and phytochemicals on antibiotic-resistant bacteria. Braz. J. Microbiol. 31(4):247-256.

On S.L., \& Harrington C.S. 2001. Evaluation of numerical analysis of PFGE DNA profiles for differentiating Campylobacter fetus subspecies by comparison with phenotypic, PCR and 16S rDNA sequencing methods. J. Appl. Microbiol. 90:285-293.

Prescott J.F. \& Bagott J.D. 1993. Aminoglycosides and Aminocyclitos, p.144178. In: Antimicrobial Therapy in Veterinary Medicine. 2nd ed. Iowa State University Press, Ames.

Quinn P.J., Carter M.E., Marrey B. \& Carter G.R. 1994. Campylobacter, p.268272. In: Quinn P.J., Carter M.E., Marrey B. \& Carter G.R. (ed.) Clinical Veterinary Microbiology. Wolfe, London.

Shin S., Kaproth M., Lein D., Arlitsch H. \& Howe B. 1985. Whole milk extender with antibiotics to eliminate Campylobacter fetus from frozen semen. J. Dairy Sci. 68(5):1280-1285.

Travers K. \& Barza M. 2002. Morbidity of infections caused by antimicrobialresistant bacteria. Clin. Infect. Dis. 34(3):131-134.

Tremblay C., Gaudreau C. \& Lorange M. 2003. Epidemiology and antimicrobial susceptibility of 111 Campylobacter fetus subsp. fetus strains isolated in Québec, Canada, from 1983 to 2000. J. Clin. Microbiol. 41(1):463-466.

Vargas A.C., Costa M.M., Vainstein M.H., Kreutz L.C. \& Neves J.P. 2003. Phenotypic and molecular characterization of bovine Campylobacter fetus strains isolated in Brazil. Vet. Microbiol. 93:121-132. 